\title{
«El signo de Jonás»
}

«Pues mientras los judíos piden señales y los griegos buscan saber, nosotros predicamos un Mesías crucificado, para los judíos un escándalo, para los paganos una locura; en cambio para los llamados, lo mismo judíos que griegos, un Mesías que es portento de Dios y saber de Dios».

(1Cor vv. 22, 23 y 24).

\section{INTRODUCCIÓN}

La intención de este trabajo es hacer un estudio diacrónico sobre el símbolo de Jonás. Digo símbolo, porque Jonás, ya desde el comienzo de su existencia literaria fue símbolo de una profunda experiencia religiosa, que se ha ido enriqueciendo y profundizando a lo largo de los siglos hasta nuestros días. En estas líneas pretendo describir cómo dicho símbolo evolucionó y se enriqueció con nuevos significados desde su origen hasta que fue utilizado por los escritores del Nuevo Testamento. La intención que lo guía no es puramente erudita, pues pretende llegar a captar las resonancias que dicha figura tuvo para ellos, y así descubrir mejor su significado.

Dejemos bien sentado desde el principio, que el estudio diacrónico no es la palabra definitiva sobre la interpretación de un texto tal como aparece en los diversos momentos, pues el hecho mismo de que un tema se repita en distintas épocas, quiere decir que es significativo para la experiencia concreta de cada una de ellas. Esto vale especialmente para el caso del N.T., a cuya base se encuentra una experiencia absolutamente nueva y transformadora, que hace que toda la historia de Israel sea leída en una nueva clave. Este tipo de estudio proporciona sugerencias, materiales, resonancias de las palabras y las figuras 
bíblicas, e incluso nos dice cómo interpretaron los autores del N.T. a la luz de la experiencia pascual dichas palabras o personajes. Sin embargo, ha de ser corregido y situado adecuadamente por un estudio sincrónico, que tenga en cuenta el estilo, el modo de usar el A.T. y la teología de cada uno de los autores. Si los evangelios son escritos teológicos no podemos interpretarlos al margen de sus intenciones y de su contexto '.

\section{ESTADO DE LA CUESTIÓN ${ }^{2}$}

En los evangelios sinópticos encontramos cuatro perícopas sobre la petición de un signo que los judíos hicieron a Jesús: Mt 12,38-42; Mt 16,1-4; Mc 8,11-13; y Lc 11,29-32. En todas ellas se hace alusión al signo de Jonás excepto en la de Marcos. Mt 16,1-4 sigue de cerca el texto y la disposición de Marcos; sin embargo Mt 12 y Lc 11 explican en qué consiste dicho «signo de Jonás» y añaden dos perícopas sobre el juicio: la reina del Mediodía que visitó a Salomón y los ninivitas que se convirtieron por la predicación de Jonás. El problema surge al constatar la diversidad, al menos aparente, entre la interpretación de Lucas y la de Mateo.

En torno a estos textos se han suscitado en la moderna investigación tres

1. Para hacer más ligero el aparato crítico, citaré las fuentes utilizadas, según la siguiente relación de

\section{SIGLAS}

CHARLES R.H. ChARLES, "The Apocrypha and Pseudo-epigrapha of the O.T.», Oxford 1913, vol. I y II.

STRACK-BILL. H.L. STRACK-P. BILLERBERCK, «Kommentar zum neuen Testament aus Talmud und Midrash», München 1920-1928, vol. I-V.

FRIEDMANN «Midrash Rabbah», translated into english by Rab. Dr. H. FRIEDMANN and M. SimON, London 1961, $3^{\text {a }}$ ed. (citado según el vol.).

DAMBY

«The Mishnah», translated from hebrew with introduction and brief explanatory notes by H. DAMBY, Oxford 1933.

LEVINE E. LEVINE, «The aramic version of Jonah» Jerusalem 1975.

ALAND K. ALAND, «Synopsis Quattuor Evangeliorum» Stuttgart 1976, $9^{\mathrm{a}}$ ed.

FUNK «Patres Apostolici», Editit F.X. FUNK, Tubingae 1901. Ed. $2^{\text {a }}$ adaucta et emendata, vol. I y II.

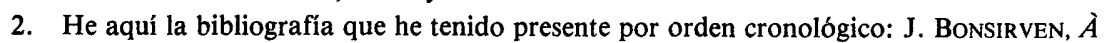
propòs du logion sur le signe de Jonas, RSR 24 (1934) 450-455. J. JEREMIAS, art. «Iōnâs» en TWzINT III, 410-413. P. SEIDELIN, Das Jonaszeichen, St. Th. 5 (1951) 119-131. K. STENDAHL, "The School of St. Matew», Upsala 1954. R. GundRY, "The use of the O.T. en St. Matew's Gospel». St. to N.T. n. ${ }^{\circ}$ 11. 1967. R.S. MacConnell, «Law and Prophecy in Mt's Gospel. Basel 1969. R.T. FRANCE, "Jesus and the O.T.» London 1971. 
tipos de problemas: problema filológico, problema de crítica literaria y el problema del significado de esta expresión.

1. El problema filológico radica en saber cuál es el significado exacto del genitivo «toû Iönâs»; si se trata del signo dado en Jonás, del signo que dio Jonás, o bien del signo, que es Jonás ${ }^{3}$.

2. A nivel de la crítica literaria el problema consiste en averiguar cuál es la explicación originaria del susodicho signo, la de Mt 12,40 o la de Lc 11,30. Aquí los autores se dividen en dos grupos.

Quienes opinan que Lucas es original (Stendahl, MacConnell) se basan en los siguientes argumentos: 1 . Mt 12,40 rompe la continuidad entre los versos 39 y $41 ; 2$. Lc no recoge esta cita explícita del libro de Jonás; 3 . Justino (Dial. $107,1)$ cita el texto de Mt y lo refiere a la resurrección, pero tampoco recoge la cita explícita de Jon 2,$1 ; 4$. Lc nos transmite el orden más difícil en las perícopas en que coincide con Mt. y por tanto el auténtico. Según esta opinión la cita explícita de Mt 12,40 no es sino una interpolación posterior, o bien de un redactor de "Q», o bien del mismo Mateo.

Por el contrario, quienes son de la opinión de que Mateo representa el texto más antiguo (Gundry, France), responden a los anteriores diciendo que: 1. La ruptura de la continuidad se basa en el prejuicio de que el signo es la predicación, pero ¿Y si el signo se refiere a Jesús mismo?; 2. Lucas no tiene la cita de Jon 2,1 porque sus destinatarios no eran judíos, y difícilmente podían entender, como entendían los judíos, que «tres días y tres noches» puede referirse también a dos noches, un día entero y parte de los otros dos días, que fue precisamente el tiempo que Jesús estuvo en el sepulcro; 3. Justino no lo trae por idéntica razón, pero lo deja adivinar cuando dice que Jesús les habló a los judíos «parakekalumména», de modo que podían haber entendido que se refería a su muerte y resurrección.

Antes de esta discusión Jeremias proponía ya dos dificultades decisivas a la primera opinión: Lucas habla en futuro («éstai»), y «sémeíon» se refiere a un signo de parte de Dios. Por eso el signo de Jesús no podía ser su predicación actual.

3. A este nivel el problema consiste en saber qué significaba o a qué se refiere la expresión «signo de Jonás». Quienes se preocuparon de este problema (Bonsirven, Jeremias y Seidelin) fueron a buscar la solución a la literatura judía anterior al N.T., incluido el mismo libro de Jonás.

Fundamentalmente dieron dos soluciones: a) Bonsirven partiendo de un texto de la Mishnah (Ta'anit II, 1.4) propone que el signo que pidieron a Jesús

3. M. ZERWICK, «Biblical Greek» Roma 1963, n. ${ }^{\circ} 45$. 
era la lluvia, pues en tiempos de sequía se organizaban ayunos, en cuyos cultos estaba presente el recuerdo de Jonás; b) La otra solución, propuesta por Jeremias y seguida fundamentalmente por Seidelin con algunos matices, afirma que dicho signo, tanto en Mateo como en Lucas, consiste en la legitimación del enviado de Dios, a través de su salvación de la muerte ${ }^{4}$, sin embargo el texto que mejor responde al contexto rabínico es el de Mateo.

Esta breve presentación del estado del problema nos indica por dónde hemos de guiar nuestro estudio. En efecto, el problema de la crítica literaria se acaba en sí mismo y es un poco ficticio. Todo parece indicar que hemos de dirigir nuestra mirada a la literatura rabínica y demás escritos judíos, que son el contexto inmediato de los evangelios. Desde ahí podremos iluminar el aspecto filológico y tal vez la discusión literaria; pero sobre todo lo que nos interesa es descubrir, a través de sus resonancias, el sentido de las palabras del Evangelio.

\section{EN LA LITERATURA JUDÍA}

El libro de Jonás es un «midrash profético basado en II Re 14,25-28, donde se habla de un cierto Jonás, hijo de Ammitay, profeta de buen agüero en tiempos de Jeroboam II de Israel. Fue escrito alrededor del siglo v y refleja una mentalidad abierta, según la cual el Dios de Israel es también Dios de los gentiles, es Dios de quien se convierte de corazón. Finalmente posee, como rasgos característicos numerosas acciones milagrosas y un salmo de lamento al estilo de los antiguos salmos hebreos 5 .

Dentro del A.T. no encontramos citado el libro de Jonás en ninguna parte ${ }^{6}$, sin embargo, se advierte una semejanza muy grande entre el capítulo 2 y los salmos de lamento, tanto estructural, como en los contenidos. Y esto mismo podemos afirmar de la literatura de Qumram.

En la literatura intertestamentaria encontramos una alusión a Jonás en IV Esdras 6,8 ${ }^{7}$ en una oración que pide la liberación del opresor: «... y cuando Jonás gemía abandonado en el vientre del monstruo marino, Tú le salvaste». El targum es una traducción casi literal del texto hebreo con leves matices que carecen de interés para nuestro tema ${ }^{8}$.

En contraste con esta parquedad, la literatura rabínica lleva a cabo una

4. Cfr. J. JeREMias, a.c. p. 413.

5. A. SogGIN, «Introduzione all'A.T.» Brescia 1979, p. 487-492.

6. Tan sólo en Tob 14 se hace alusión a Nínive como el prototipo de la ciudad pecadora. Pero más que una reinterpretación, hemos de ver aquí un tránsfondo común.

7. Charles I, 171.

8. La aparición del término «menra» en 2,5 y 3,4. Cfr. LEVINE p. 50-51. 
especulación muy iluminadora sobre la figura de Jonás, que se refiere o bien a Jonás 1-2, o bien a Jonás 3 .

-Están relacionados con el ayuno y la conversión (Jon 3) el texto, ya aludido, de Ta'anit II, 1.4. en el que encontramos esta monición, a los ritos de ayuno:

«Hermanos, no está escrito de los ninivitas que Dios vio sus vestidos de saco y su ayuno, sino 'y Dios vio sus obras y que se convertían de su mal camino'» $(\mathrm{II}, 1)$

Y en la sexta bendición:

«Que él, que escuchó la voz de Jonás en el vientre del pez, escuche el clamor de tus gritos hoy. Bendito seas tú, Señor, que respondiste en el día aciago» $(\mathrm{II}, 4)^{9}$

Relacionado con este mismo tema leemos en el Midrash de las Crónicas (Intr. 31):

«Envié a Nínive un profeta, y él les hizo convertirse de su pecado. Y ¡Cuántos profetas he mandado a Jerusalén a los israelitas!» ${ }^{10}$.

- Los textos que se refieren a la figura y las peripecias de Jonás (Jon 1-2) son mucho más numerosos. En Pirqe de Rab. Eliezer, 33 se le identifica con el hijo de la viuda de Sarepta a quien Eliseo resucitó ". En el Midrash a los Salmos 26,17 se dice que es el «Justo Perfecto» que visitó el «Jardín de Edén» en vida ${ }^{12}$. De nuevo en Pirqe de Rab. Eliezer (cap. 10) encontramos una desarrollada especulación que toma como base los motivos míticos que se encuentran en el salmo del cap. 2, y describe una leyenda fantástica del viaje de Jonás a los lugares inferiores, en la que aparece Leviatán (el monstruo marino mítico) y la Gehenna, o lugar del castigo ${ }^{13}$. La idea de que Jonás arriesga su vida para inducir a Dios a castigar a su pueblo, y luego se entrega a sí mismo en favor de éste, la encontramos en Rab. Jonathan, que vivió hacia el año $140^{14}$.

Finalmente he aquí dos textos que me parecen muy importantes. El primero muestra que para los judíos el signo de Jonás consistía en los grandes

9. Cf. DAMBY, 195 y 196. Sobre este texto funda Bonsirven su propuesta de interpretación. En su breve pero sugerente artículo (a.c) demuestra que Jonás era aludido en las liturgias de los ayunos y que estos estaban en vigor en tiempos de Jesús. Su interpretación de Mt 16,1ss desde este contexto me parece muy plausible, pero creo que para Mt 12,38 ss se trata de un asunto diferente.

10. StRACK-Bill, I, 651 .

11. También en Midr.Tehill. 26,17.

12. Con lo que eso significaba respecto de la inmortalidad en la especulación rabínica. Cfr. también SEIDELIN, a.c. p. 126-127.

13. Cfr. SEIDELin, a.c. p. 124-125.

14. Mek. Ex 12,1 lb y 2a. Cfr. Seidelin, 124 y Jeremias, 411. 
prodigios que Dios había realizado con él. Lo encontramos en Rab. Meïr (hacia 150):

«Entonces dio Dios orden al pez de que expulsara a Jonás. Vieron los marineros todos estos signos y los grandes prodigios que hacía Yavé con Jonás y enseguida se levantaron y cada uno lanzó al mar la estatua de su Dios» ${ }^{15}$.

El segundo es una lista de las acciones salvadoras llevadas a cabo por Dios en la historia de Israel, que tienen como sello de su intervención el haber sido realizadas «al tercer día». Se encuentra en tres lugares de los grandes comentarios: GenR 56,1; GenR 91; y EsthR 9,2. A propósito de Gen 22,4 se comenta así:

«AL TERCER DÍA. Está escrito 'después de dos días él nos hará revivir, al tercer día nos levantará para que podamos vivir en su presencia' (cf Os 6,2), es decir, al tercer día de los antepasados tribales (y cita Gen 42,18 aludiendo a José); al tercer día de la revelación (cita Ex 19,6 haciendo alusión a la revelación de Dios al pueblo); al tercer día de los espías (cita Jos 2,19 haciendo alusión a la conquista de la tierra prometida); al tercer día de Jonás (cita Esdr 7,32). Al tercer día de la resurrección (cita de nuevo Os 6,2); en el tercer día de Ester (cita Est 5,1)» (GenR 56,1) ${ }^{16}$.

Una lista muy parecida encontramos en el comentario a Ester 5,1 introducida con estas palabras «Nunca Israel fue dejado en su desgracia más de tres días» (EsthR 9,2) ${ }^{17}$.

Así pues, la literatura rabínica muestra más interés por Jon 1-2, que por la conversión narrada en el capítulo 3 ; y parece que en el contexto judío el «signo de Jonás» se refería, no a su predicación o a su persona, sino a las maravillas que Dios había obrado en él.

Antes de proseguir hemos de dar respuesta a una seria objeción que salta inmediatamente de los textos: tanto la especulación sobre Jon 1-2, como los textos de los grandes comentarios, se remontan a una época tardía. Esto es cierto, pero no es menos cierto que las alusiones míticas están presentes en el mismo salmo ${ }^{18}$ y que la actuación salvífica de Dios «al tercer día está presente en el A.T. El tercer día es el día de salvación (Os 6,2) o es el día de la manifestación de Dios:

«Al tercer día, al rayar el alba hubo truenos y relámpagos y una densa nube sobre el monte y un poderoso resonar de trompeta y todo el pueblo que esta-

15. Pirqe R. El. 10 (Strack-Bill. I, 646).

16. FRIEDMANN I, 491.

17. FRIEDMANN IX, 112

18. No hemos de olvidar la relación de éste con los salmos de lamento, pues esta relación es 
ba en el campamento se echó a temblar. Moisés sacó al pueblo del campamento a recibir a Dios. El monte Sinaí era todo una humareda porque el Señor bajó a él con fuego...» (Ex 19,16-18).

Lo único que hicieron los Grandes Midrashim fue poner en una lista dichos textos. Según esto, ambos datos que se encuentran con suficiente claridad ya en el A.T. e incluso es posible que los textos rabínicos que los comentan procedan de una época anterior a aquella en que fueron escritos en las grandes colecciones.

\section{En el Nuevo Testamento}

En el N.T. encontramos una cita explícita de Jon 2,1 en Mt 12,40, alusiones claras en Mt 12,39.41; Mt 16,4; y Lc 11, 29.30.32; y una velada alusión al capítulo primero en la perícopa de la tempestad calmada (Mc 4,35-41 y par.).

1. Existe un gran paralelismo entre Jon 1 y Mc 4,35-41 ${ }^{19}$, no sólo en el tema de la narración, sino también a nivel de vocabulario: ${ }^{20}$.

$\begin{array}{lll}\text { Jon 1,4 } & \text { Mc 4,37 } & \\ \text { Jon 1,5-6 } & \text { Mc 4,38a } & \text { (katheúdo, apollymi) } \\ \text { Jon 1,11-12 } & \text { Mc 4,39b } & \text { (kopáo) } \\ \text { Jon 1,10.16 } & \text { Mc 4,41 } & \text { (ephobéthēsan phóbon mégan) }\end{array}$

2. En Mt 12,41 y Lc 11,32 se alude a la conversión de los ninivitas exactamente con las mismas palabras. Ambos evangelistas coinciden también en la respuesta de Jesús: «no les darán otro signo, que el signo de Jonás» y Mt añade «el profeta» (Mt 12,39b; Lc 11,29b).

Se trata de dos alusiones distintas. Una es la respuesta a la petición de un signo y la otra una alusión a la ejemplar conversión de los ninivitas. Esta última no plantea especiales problemas en su comprensión: Jesús increpa a su generación recordándoles el ejemplo de los hombres de Nínive, la ciudad pecadora, que se convirtieron con la predicación de Jonás y remite al juicio su actitud, pues no se convierten con sus palabras y él es más que Jonás. Pone de manifiesto la supremacía del «antitipo» Cristo sobre el «tipo» Jonás y se hace re-

muy importante para comprender adecuadamente la cita de Mt 12,40 como veremos en el apartado siguiente (cfr. supra).

19. Las alusiones son mucho más claras en Mt y en Lc, pero ahora examinamos el relato de Mc, pues nos interesa resaltar que también él tiene presente el libro de Jonás.

20. Aquí señalamos tan sólo las concordancias literales, a nivel de sinónimos la semejanza es mayor. De cualquier modo parece hoy aceptado como un hecho que el libro de Jonás influyó en la estructuración de este relato. 
ferencia a un elemento apocalíptico: el juicio, que junto con el título «Hijo del hombre» (Mt 12,40 y Lc 11,30) nos sitúan en la clave de lectura apocalítica de los autores del N.T.

La otra alusión, la de Mt 12,39b y Lc 11,29b, es la respuesta enigmática de Jesús a quienes le acusaban de expulsar los demonios con la fuerza de Belzebul (Mt 12,24 y par.) y le pedían un signo para que creyeran que obraba con el dedo de Dios. De este modo nos introducimos en la cuestión de la aparente divergencia de interpretación en Mateo y en Lucas de dicho «signo de Jonás».

3. ¿Cuál es el signo de Jonás? J.H. Michael propuso una corrección y pensaba que el signo no se refería a Jonás, sino a Juan ${ }^{21}$. La exégesis tradicional pensó que se refería a la predicación ${ }^{22}$. Finalmente J. Jeremias, seguido y matizado por Seidelin y otros propuso que el signo es el episodio narrado en Jon 2. Veamos en primer lugar una comparación entre los textos de Mateo y de Lucas:

Mateo 12,40

Hösper gar èn Iōnâs

en té koilía toû kètous

treîs hemerais kaì treîs

nýkas

houtōs éstai ho huiós

toû anthropou

en tē kardía tès gēs

treîs hëmerais kaì

treîs nýktas

\section{Traducción:}

Pues como estuvo Jonás

en el vientre del pez

tres días y tres noches

Así estará el Hijo del

Hombre

en el corazón de la tierra

tres días y tres noches

(Mt 12,40)
Lucas 11,30

Kathōs gar egeneto Ionnâs

tô̂s Nineuítais sémeîon

houtoss éstai ho huiós

toû anthropou

tè geneā taútē
Pues así como Jonás fue un signo para los habitantes de Nínive

Así será el Hijo del

Hombre

para esta generación

$(\operatorname{Lc} 11,30)$

Las discrepancias radican fundamentalmente en que Mt, partiendo de una cita literal del libro de Jonás, afirma que el Hijo del hombre será el signo

21. J.H. MichaEL The sign of John, JThSt. 21 (1920) 149-151.

22. Cfr. J. JEREMIAS, a.c. p. 412. 
con su permanencia de tres días y tres noches «en el corazón de la tierra»; mientras que Lc, responde oscuramente que el Hijo del hombre será el signo, sin especificar cómo ${ }^{23}$.

La interpretación de Mt nos trae a la memoria enseguida un paso concreto de la historia de Jonás. En efecto, en la cita de Jonás 2,1 tenemos una alusión implícita a todo el capítulo, es decir, al salmo y a la liberación de Jonás por orden de Dios ${ }^{24}$; y por tanto para entender correctamente el texto de $\mathrm{Mt}$ hemos.de tener presentes el cap. 2 de Jonás y los salmos de lamento relacionados con él, así como las resonancias de esta parte de la historia de Jonás en la literatura judía, las cuales, como ya hemos visto, son las más numerosas.

Para la literatura rabínica el signo de Jonás consistía en el prodigio obrado por Dios en Jonás ${ }^{25}$, que fue conocido por los marineros y también por sus familiares ${ }^{26}$, y por tanto nada de extraño tiene que lo fuera también por los habitantes de Nínive. Por eso Jesús no compara su predicación con la de Jonás, sino su signo, su confirmación de parte de Dios con el signo de Jonás. Además toda la especulación mítica de bajada al sheol, que se hace en torno a Jon 1-2 tiene que ver con la experiencia, narrada en los salmos de lamento, de la muerte inminente y segura, de la cual Dios libra a quien le suplica. Finalmente la expresión "al tercer día» que encabeza la lista de las acciones salvadoras de Dios con su pueblo en GenR 56,1 y par. es el signo de la presencia de Dios en la vida de Jesús.

Así iluminado, el texto del evangelio adquiere nuevas resonancias. Mateo nos dice: la señal de que Jesús actúa con el «dedo de Dios» es su permanencia de tres días en los dominios de la muerte, al cabo de los cuales, Dios, culminando su larga historia salvadora, lo resucitará. La insistencia en la expresión «tres días y tres noches» no es ociosa, es el signo de la acción salvadora de Dios ${ }^{27}$.

4. El análisis de los textos nos conduce hasta uno de los primeros problemas con los que se encontró la teología cristiana: explicar la contradicción que

23. En el primer apartado de este trabajo ya hemos mostrado que no puede referirse a la predicación (p. 4).

24. Se trata de un modo común de citar entre los judíos y también entre los cristianos. (Cfr. Ch.H. DodD «Secondo le scritture» Brescia 1972, p. 63).

25. Vid. apartado $2 .^{\circ}$ de este trabajo pp. 7-8.

26. III Mac 6,8. Cfr. J. JeREMIAS, a.c. 413.

27. La respuesta de Lucas es prácticamente la misma, pues sēmeion se refiere a una acción de Dios y el futuro éstai remite dicho signo al futuro. Es posible que Mt refleje el texto original y Lc, por dificultad de comprensión en sus oyentes (cfr. apart. 1) haya resumido. De cualquier modo vemos que la respuesta es prácticamente la misma, aunque Mt refleja una preocupación teológica muy temprana y una gran consonancia con el ambiente judío que le rodeaba. 
suponía para la mentalidad judía un Mesías sufriente. San Pablo (1Cor 1,2224) se hace eco de este «escándalo de la cruz». Lucas responde por boca del mismo Jesús que «era necesario que el Mesías padeciera» (cfr. Lc 24,26); y Mateo responde que no sólo no es un escándalo, sino que esta permanencia en los dominios de la muerte es el «signo de que Dios actúa en Jesús».

Para explicar este dato fundamental del kerigma cristiano, los primeros «teólogos» buscaron una respuesta en las escrituras y la hallaron en los cantos del «siervo sufriente» de Isaías, en los salmos de lamento, sobre todo en el salmo 22 y la expresión «al tercer día» como signo de la acción salvadora de Dios.

La expresión «al tercer día» es una frase ya hecha en el kerigma prepaulino: «al tercer día según las escrituras» (cfr. 1Cor 15,3-5). Esta misma expresión o el número tres se encuentra presente en los relatos sinópticos de la pasión en una proporción muy superior a la del resto de los relatos evangélícos: Mt utiliza 16 veces el $n .^{\circ}$ 3, 11 de las cuales se refieren a la pasión; Mc 11 , de las que 9 están en relación directa con la pasión; Lc en fin, lo utiliza 35 veces de las cuales 9 tienen que ver con la muerte y resurrección de Jesús ${ }^{28}$.

A mi modo de ver también el texto de Mateo 12,40 y la perícopa entera se inscribe en este contexto general, detrás del cual resuenan las listas de GenR 56,1 , etc., como una tradición que resumía el signo de la intervención de Dios que salvaba a su pueblo «al tercer día», la cual alcanza su punto culminante en la intervención de Dios resucitando a Jesús de la muerte «al tercer día según las escrituras». La resurrección es, pues, el signo definitivo de que Dios actúa a través de Jesús. La aceptación de este signo es necesaria para llegar a la fe en Jesús, y así fue como surgieron las comunidades cristianas llenas de vida cuando aceptaron y experimentaron la resurrección.

La historia de Jonás como símbolo de la resurrección de Jesús perduró entre los cristianos. De ella se hacen eco san Ignacio de Antioquía (AdTrall

28. He aquí un cuadro detallado de dicho uso:

$\begin{array}{lrrr}\text { Al tercer día resucitaré } & \text { Mt } & \text { Mc } & \text { Lc } \\ \text { Signo de Jonás } & (4) & (3) & 4) \\ \text { Destruc. y reconstruc. del templo } & (1) & & \\ \text { Custodia del sepulcro } & (2) & (2) \\ \text { Al tercer día soy consumado } & (1) & & \\ \text { Van tres días (Emaús) } & & & \\ \text { Oración en el Huerto } & & & (1) \\ \text { Negaciones de Pedro } & (1) & (1) & \\ \text { Crucificado a la tercera hora } & (2) & (2) & (2) \\ \text { Pilatos pregunta por tercera vez } & & (1) & \\ \end{array}$


9,5-6) ${ }^{29}$, san Justino (Dial. 107,1) ${ }^{30}$. Pero su exuberancia significativa se despliega en las comunidades cristianas sencillas, pues se trata de un signo sencillo y gráfico. En las pinturas de las catacumbas romanas se halla profusamente representado dicho signo. Poco a poco se fue haciendo de dicha historia una alegoría de la vida cristiana, manifestando así la esperanza de que creemos que lo que se realizó en el Señor Jesús se ha realizado ya en nosotros y se realizará de modo pleno en la resurrección del último día.

\section{CONCLUSIÓN}

Hemos descrito la evolución del símbolo de Jonás hasta la época del N.T. El personaje histórico, el nacimiento del libro como «midrash profético», la historia de Jonás vista por la literatura rabínica, $y$, finalmente, su aparición en los evangelios sinópticos. Al final quisiera resaltar algunos matices que interesan para comprender el significado de las palabras del evangelio, y en los cuales, a mi modo de ver, no se ha insistido suficientemente.

1. Mat 12,40 no cita tan sólo Jon 2,1, sino que se refiere a todo el capítulo 2. El salmo del capítulo segundo está relacionado estrechamente con los salmos de lamento $(6,22$, etc...), que describen la oración del justo a Dios y su respuesta salvadora. Los cristianos de la primera generación vieron en estos salmos, al menos en el salmo 22 con toda seguridad, un anticipo de la Pascua de Jesús, y a la luz de ellos interpretaron la pasión del Señor.

2. La literatura rabínica se ocupa sobre todo de Jon 1-2 como han notado Jeremias y Seidelin, pero no se ha insistido aún en la importancia del texto de GenR 56,1 y par. (presente en tiempos de Jesús al menos en lo que supone de tradición veterotestamentaria) para interpretar la expresión «al tercer día» y su frecuencia en las tradiciones sobre la pasión. Dicha expresión no se basa

29. «El día de la preparación, a la hora de tercia, recibió la sentencia de Pilato con el consentimiento del Padre, a la de sexta fue crucificado, a la de nona exhaló el espíritu. Antes del ocaso del sol fue bajado de la cruz y sepultado en un sepulcro nuevo. El sábado ciertamente permaneció bajo tierra en el sepulcro, en el cual le había colocado José de Arimatea. El domingo resucitó de los muertos, según lo que había dicho: 'Como estuvo Jonás tres días y tres noches en el vientre del pez, así estará el Hijo del Hombre en el corazón de la tierra tres días y tres noches' (cita literal de Mt 12,40). Comprende el día de la preparación: su pasión; el sábado: la sepultura; y el domingo: la resurrección».

30. «Y como había de resucitar al tercer día después de ser crucificado, se escribe en los recuerdos de los apóstoles que; discutiendo con Él los de vuestro pueblo, le dijeron: 'Muéstranos un signo', a lo que respondió: 'esta generación mala y adúltera busca un signo y no se le dará otro signo que el de Jonás el profeta'. Y aunque esto les dijo ocultamente, todavía podían haber entendido los oyentes que después de crucificado resucitaría al tercer día». 
tan sólo en Os 6,2 como comúnmente se acepta, sino que tiene un contexto más amplio de textos del A.T. entre los cuales se halla, como hemos visto, Jon 2.

3. El hecho de que el libro de Jonás esté presente, no sólo en Mateo y en Lucas, sino también en Marcos, induce a pensar que al menos dos fuentes distintas (Mc y Q) conocen y tienen en cuenta el relato y la historia de Jonás. Según los requisitos establecidos por Dodd tenemos en el libro de Jonás un «testimonium» utilizado por los primeros cristianos para explicar el «kerigma», que ha de ser añadido a los ya enumerados por el mismo Dodd ${ }^{31}$.

Creo que tanto el texto de Mateo como el de Lucas han de ser leídos a la luz de estas consideraciones, pues efectivamente, a la luz de sus resonancias veterotestamentarias y de la cultura judia, encontramos una serie de matices que la distancia en el tiempo ha hecho que vayamos perdiendo. De este modo podemos volver a descubrir la frescura y el profundo significado de este signo del nuevo Jonás.

Santiago GUIJARRO OPORTO

31. O.c., en la cual se hace alusión tan sólo al libro de Oseas como transfondo de la expresión «al tecer día según las escrituras» (p. 80). 